\title{
Educational sector and labor market of the European Union: problems and prospects
}

\author{
Vladislav Belov ${ }^{1}$ and Natalia Govorova ${ }^{1,2, *}$ \\ ${ }^{1}$ Institute of Europe of the Russian Academy of Sciences, 125009, Moscow, Russia \\ ${ }^{2}$ Moscow Technological Institute, 199334, Moscow, Russia
}

\begin{abstract}
The article examines the problems and prospects of professional education in the European Union as an instrument of human development and labor market. The trends of recent years are analyzed - a significant increase in demand for high-skilled workers (on the background of high unemployment among young people) that occurred as a result of progress in information and communication technologies, development of "green economy", competition of goods and services (including education) and labor market on the global stage. Questions of educational policy are mainly under the jurisdiction of national states. In the current context the EU authorities and governments of member countries intend to strengthen cooperation at the European level, relations within educational services market and the needs of the postindustrial economy, optimize professional skills, especially among the younger generation, and create an open innovative digital learning environment for different groups of the population throughout life. Taking this into consideration it is necessary to focus the efforts on the solution of the number of internal challenges, demographic, migratory, economic and technological challenges on a global scale.
\end{abstract}

\section{Introduction}

The European Union has the competence to support, harmonize or enhance the actions of the Member States at the area education, vocational training, youth and sport. The EU supports development of high quality education, including distance learning, the exchange of best practices, cooperation of member States, coordinates their actions, and contribute to the strengthening of pan-European format in education, mobility of students and teachers and harmonization of training standards (recognition of diplomas and study periods). In the field of professional education, the EU is responsible for the optimization of vocational training in the light of structural changes in the budget allocation, training and retraining of staff, promotes dialogue between schools and companies, exchange of information and experience. National governments commit themselves on the content of the learning process and functioning of the education system.

The activity of the European Union in the field of education is affected by globalization, acceleration of and advances in technological development. So, economic priorities are playing an increasingly significant role. Current challenges in this field are the formation of economy based on knowledge and the promotion of adults' lifelong learning.

The Directive 2005/36/EC of the European Parliament and of the Council of 7 September 2005 on the recognition of professional qualifications became valid in 2007. It is the base of the EU legislation in this area, which includes some of the sectoral and general directives. Directive consists of different procedures for mutual recognition of diplomas, depending on the type of employment (permanent or temporary), relevant to more than 800 professions (all healthcare professions, most construction, commercial and industrial specialties), excepting following specialists: lawyers, accountants, insurers, all transport specialties, etc.; their activity is regulated by other normative acts of the Union.

The strategy for cooperation of the EU countries in the field of education and training (Strategic Framework for European Cooperation in Education and Training 2020) adopted in 2009. One of the main objectives of the program is the improvement of the quality of education and training, the enhancement of labor mobility, the expansion of learning opportunities throughout life and gender equality. By 2020 at least $95 \%$ of children older than four years old should be educated in programs of preschool education; the share of 15-year-old adolescents who are not achievers in reading, mathematics and science - not to exceed 15\%; at least $40 \%$ of young people (30-34 years) have a higher education; at least $15 \%$ of adults to training throughout life; below $10 \%$ should be the percentage of students aged 18-24 years had completed secondary education.

To improve competitiveness, social sphere, prosperity and equality in the European society, the heads of states and governments of the 27 EU countries endorsed the Strategy Europe 2020 in June 2010 - a program to stimulate growth and employment. In the

Corresponding author: $\underline{\text { n govorova@mti.edu.ru }}$ 
sphere of education and science the Strategy is focused on combined public and private investment levels to reach $3 \%$ of EU's GDP as well as better conditions for R\&D and Innovation; better educational attainment - in particular: reducing school drop-out rates below $10 \%$, at least $40 \%$ of $30-34$-year-olds with third level education (or equivalent); reducing school drop-out rates below $10 \%$.

These areas are addressed by four flagship initiatives. The Innovation Union - over 13 action points published on 6 October 2010 (promoting excellence in education and skills development; delivering the European Research Area; focusing EU funding instruments on Innovation Union priorities; promoting the European Institute of Innovation and Technology as a model of innovation governance in Europe; enhancing access to finance for innovative companies; creating a single innovation market; promoting openness and capitalizing on Europe's creative potential; spreading the benefits of innovation across the Union; increasing social benefits; pooling forces to achieve breakthroughs: European Innovation Partnerships; leveraging our policies externally; reforming research and innovation systems; measuring Progress). Youth on the Move purposes to expand young people's education and employability, to shrink high youth unemployment and to rise the youthemployment rate by: making education and training more relevant to young people's needs; inspiring them to be more mobility; simplifying the transition from education to work. Digital agenda for Europe aims the creation of a single digital market of the EU to increase access of citizens and companies, the provision of social service. An Agenda for new skills and work intentions modernization of the labor market, the improvement of the relationship of supply and demand, the possibility of obtaining new knowledge and skills.

Some countries have already achieved the targets of the Strategy 19 countries have already coped with the task of reducing the number of young people who left education or less only in Croatia, Poland, Czech Republic, Slovenia (5.5\%). Leaders in higher education to date, to admit Lithuania, Luxembourg, Cyprus and Ireland (over 50\%), outsiders - Italy, Romania, the Czech Republic, Slovakia and Malta (30\%); R \& d expenditure has exceeded the target only in Sweden, Finland and Denmark, are approaching this indicator, Germany, Austria and Slovenia, hopelessly lagging behind Romania, Cyprus, Bulgaria and Latvia.

\section{Analysis of the problems and prospects}

In Europe the demand for jobs requiring digital skills is rising quickly $[1,2]$; the demand for jobs that require digital skills is growing rapidly - and, by 2020 Europe could have a shortage of one million professionals. The Commission has recognized ICT as one of three employment growth zones. A new study «e-Skills in Europe: measuring Progress and Moving Ahead» illustrates the tendency towards higher-level ICT skills will stay. One of the key predictions is - by 2020 the number of ICT management and analysis jobs would raise by $44 \%$ compared to 2011 , and linked jobs by $16 \%$. Mid-level technician jobs will continue to vanish as an effect of computerization and productivity gains. The revision claims that there is a matching need to increase the quality and relevance of e-skills available in the labor market. More than $60 \%$ of Europe's digital jobs openings are in Germany, France, Italy and UK.

According to the first international Survey of Adult Skills (OECD and European Commission) 1 in 5 adults in Europe has low literacy and numeracy skills, $25 \%$ of adults lack the digital skills needed to effectively use ICT. The low literacy, numeracy and problem-solving ICT skills of adults aged 16-65 in 17 EU Member States (Belgium, Czech Republic, Denmark, Estonia, Finland, France, Germany, Ireland, Italy, Cyprus, The Netherlands, Austria, Poland, Slovak Republic, Spain, Sweden and the UK) necessitates the considerable investments in skills and training, both for the young unemployed and for the lifelong learning of middle-aged and older workers. There is huge need to improve education and training and to increase skills in Member States.

The Survey of Adult Skills highlights weaknesses in education and training systems. At EU and national level, we must to invest more in better education and better training. There are remarkable differences between countries in skills provided through formal education. More than $40 \%$ of the adult population in the Netherlands, Finland and Sweden have high problem solving skills in ICT situations, while $20 \%$ of the Spaniards, Italians, Poles, Cypriots and Slovaks have no computer practice. Literacy scores from recent upper secondary school graduates in the Netherlands and Finland are better than those of higher education graduates in Ireland, Spain, Italy, Cyprus and the UK.

The new Erasmus + program for education, training and youth will support projects targeted at developing and advance adult skills. European Social Fund is a key source of investment in skill development and trainings. It can expand access to training for vulnerable groups. Lifelong learning policies must aim at sustaining skills over time given the gaps between generations revealed by the survey and the significant economic and social benefits of higher skills.

Contemporary competition is the competition in terms of quality of human capital and the method it is used in the economy. To reverse today's negative trends of human capital development the Commission uses European Skills, Competences, Qualifications and Occupations (ESCO). This tool is needed for different reasons: to improve education or training offers and working conditions, to help people find a job and make the right career choices. It will improve the functioning of European labor market. This is extremely important because the EU has to compete on world markets of goods, services, capital and workforce.

Today it is impossible to ignore increasing competition in the field of human capital side quality from China, primarily in education. The number of university graduates in China has grown from two million in 2003 to seven million in 2013. China's shares 
of people with tertiary education will escalation from $18 \%$ in 2010 to $29 \%$ in 2020 , while the USA and the EU together would account $25 \%$. Europe cannot afford to let its skills potential go to waste. The EU need to keep investing in skill formation and also in the efficiency of matching between the skills supply and companies' needs. The EU need to do this at all level of skill. The Commission is playing the coordinating role at European level, but ESCO can only be successful throughout Europe, if the EU authorities and national governments will work towards an effective implementation on state and regional level.

Besides, it should be noted that there is a serious disparity between the Union's citizens and migrants. Migrants are more than twice as likely to not finish an educational institution or vocational training $(25,5 \%)$. They bear much stronger risks to be out of education, training and employment (over 20\%). Only less than one third of migrants have completed tertiary education, which is significantly lower than among the indigenous population. At the same time, $40 \%$ of migrants have a low level of education, which is significantly higher than EU citizens. Taking this into consideration, the EU will be difficult to achieve by 2020 indicators in the field of education $[3,4]$.

Nowadays it is important to be a worker with different skills and the right education, because these people can use technology to make value. In states with an aged population, such as Greece and Spain, more than $50 \%$ of economically active young persons are unemployed, a condition deteriorated by obstinately high school dropout rates. Early school leavers account for $28 \%$ of the population ages 18-24 in Spain, compared with $14 \%$ across the EU. Young untrained employees have a much lower chance of securing full-time work.

There is also disparity between skills demanded and skills existing. A mismatch in skills is associated with a high quantity of young people not in education, employment or training. For numerous young workers the only way to employment in the formal economy is through temporary or out staffing work. They are thus more probable to be laid off because many countries in Europe enforce job protection for older permanent workers. Since the start of the crisis, in many countries there is an increase in the share young people who are neither employed nor in education or training. One result of low involvement and high youth unemployment is the late start of contributions for retirement benefits. Another is that mounting youth unemployment, mostly of the long-term category, might leave economies with a missing generation of workers.

The problem of the skills mismatch in the knowledge economy is the result of the leap of technological innovation and of the fast evolution in demand for unique and sophisticated skills. In an investigation of businesses in eight European countries, 27\% of companies informed that they could not fill vacancies because candidates lacked the required skills. Some $45 \%$ of employers in Greece and $47 \%$ in Italy reported that their businesses were disadvantaged by a lack of necessary skills.
In the EU 16 million jobs employing highly qualified people are probable to be added by 2020 , while jobs employing people with few or no formal qualifications are expected to failure by 12 million. Some jobs being created are in nontradeable services (health care, education and public services, human development). Technological advances are engines for new forms innovation. The digital revolution, and ICT systems that support it, appeared from creative and innovative work. This is mirrored in the growth of patents granted over the past decades.

However, the post-industrial economy has been going together rising inequality, unlocked a new gap between good jobs - steady and high-paying and bad jobs - short-lived and low-paying. The higher level of the education and skill level of the workforce, the higher are the wages, in general. The greater the institutionalization of labor markets, the higher is the quality of service jobs in general [5]. Educational policy of the European Union, complementing the policies of member States, is inextricably linked with the sustainable development agenda of the United Nations and aimed at strengthening the single internal market, improving the functioning of labor market, social cohesion and the growth of competitiveness of the EU in the world, the formation of common European educational area [6].

\section{Conclusion}

The actions to improve educational sector of the European Union and develop workers with new skills and education should focus on the following:

1. Upgrading skills and training for new types of work. Sophisticated skills will be needed for science and engineering jobs.

2. Increasing access to tertiary education in order to meet future demand.

3. Programs should consider skills development through education, mainly in math and science, training that matches market demands and admission to current practiced progress.

4. Using adult education programs for continued learning. Northern European countries are particularly successful at lifelong learning, with over $60 \%$ of the adult population participating in adult education in Denmark, Finland, the Netherlands, Norway and Sweden.

5. Both employers and governments may organize such programs.

\section{References}

1. D. Acemoglu, Journal of Economic Literature, 40(1), 7-72 (2002)

2. St. Machin, Oxford Bulletin of Economics and Statistics, 63, 753-776 (2001)

3. M. Czaika, Ch. R. Parsons. The Gravity of HighSkilled Migration Policie s(International Migration Institute. University of Oxford. Working Papers 110, 2015). 
4. D.G. Papademetriou, S. Will, T. Hiroyuki. Talent in the 21st-Century Economy (Washington, DC: Migration Policy Institute, 2008)

5. S. Jahan, HDR 2015 Work for Human Development (UNDP, 2015).
6. C.Adelle, M.Pallemaerts, Sustainable Development Indicators An Overview of relevant Framework Program funded research and identification of further needs in view of $\mathrm{EU}$ and international activities (2009) 